\title{
Patient Navigators Connecting Patients to Community Resources to Improve Diabetes Outcomes
}

\author{
Natalia Y. Loskutova, MD, PhD, Adam G. Tsai, MD, Edwin B. Fisher, PhD, \\ Debby M. LaCruz, MTS, Andrea L. Cherrington, MD, T. Michael Harrington, MD, \\ Tamela J. Turner, PhD, and Wilson D. Pace, MD
}

Background: Despite the recognized importance of lifestyle modification in reducing risk of developing type 2 diabetes and in diabetes management, the use of available community resources by both patients and their primary care providers (PCPs) remains low. The patient navigator model, widely used in cancer care, may have the potential to link PCPs and community resources for reduction of risk and control of type 2 diabetes. In this study we tested the feasibility and acceptability of telephone-based nonprofessional patient navigation to promote linkages between the PCP office and community programs for patients with or at risk for diabetes.

Methods: This was a mixed-methods interventional prospective cohort study conducted between November 2012 and August 2013. We included adult patients with and at risk for type 2 diabetes from six primary care practices. Patient-level measures of glycemic control, diabetes care, and self-efficacy from medical records, and qualitative interview data on acceptability and feasibility, were used.

Results: A total of 179 patients participated in the study. Two patient navigators provided services over the phone, using motivational interviewing techniques. Patient navigators provided regular feedback to PCPs and followed up with the patients through phone calls. The patient navigators made 1028 calls, with an average of 6 calls per patient. At follow-up, reduction in $\mathrm{HbA}_{1 \mathrm{c}}(7.8 \pm 1.9 \% \mathrm{vs} 7.2 \pm$ $1.3 \% ; P=.001)$ and improvement in patient self-efficacy $(3.1 \pm 0.8$ vs $3.6 \pm 0.7 ; P<.001)$ were observed. Qualitative analysis revealed uniformly positive feedback from providers and patients.

Conclusions: The patient navigator model is a promising and acceptable strategy to link patient, PCP, and community resources for promoting lifestyle modification in people living with or at risk for type 2 diabetes. (J Am Board Fam Med 2016;29:78-89.)

Keywords: Community-based Participatory Research, Diabetes Mellitus, Practice-based Research, Self Care

Despite multiple efforts to diagnose, treat, and reduce the risk of developing diabetes, nearly 29.1 million people in the United States have the disease, including 8.1 million who are undiagnosed. ${ }^{1}$

This article was externally peer reviewed.

Submitted 5 February 2015; revised 23 September 2015; accepted 25 September 2015.

From the American Academy of Family Physicians National Research Network, Leawood, KS (NYL, WDP); the Division of General Internal Medicine (AGT) and the Department of Family Medicine (WDP), University of Colorado School of Medicine, Aurora; Peers for Progress and Department of Health Behavior, Gillings School of Global Public Health, University of North CarolinaChapel Hill, Chapel Hill (EBF); YMCA of Greater Birmingham, Birmingham, AL (DML); and the Department of Medicine (ALC) and the Department of Family and Community Medicine (TMH, TJT), University of Alabama at Birmingham, Birmingham.
The American Diabetes Association (ADA) has proposed a reasonable target of $<7 \%$ for glycohemoglobin $\left(\mathrm{HbA}_{1 \mathrm{c}}\right)$ for many adults; however, significant numbers of patients do not reach treatment

Funding: This article is based on Cities for Life project that was made possible with support from Sanofi US. Sanofi US was not involved in the study design, data analysis and interpretation or reporting of this work, but reviewed the final draft of this manuscript and reviewed and approved consumer materials such as posters and brochures during study implementation.

Prior presentation: This study was presented as a poster at the 74th Scientific Sessions of the American Diabetes Association, San Francisco, CA (June 13-17, 2014).

Conflict of interest: NYL has received research support from Sanofi US, Merck, and Shire. AGT has received research support from Sanofi US and Nutrisystem, Inc. EBF has received research support from Sanofi US, Eli Lilly and Co. Foundation, and the Bristol-Myers Squibb Foundation. ALC, TH and TJT have received research support from Sanofi US. WDP has received 
goals, pointing to concerning management of diabetes. $^{2}$ Overwhelming evidence indicates that primary care can make a significant contribution to improving the delivery of care and health outcomes among populations. ${ }^{3}$ The roles of families, neighborhoods, organizations, and communities surrounding an individual are also important in supporting individual care needs. ${ }^{4}$ Many of the services needed for diabetes care, such as emotional support, education, and resources for physical activity and healthy eating, can be provided by community organizations. Community-based interventions have demonstrated success in promoting physical activity, ${ }^{5}$ weight management, and healthy eating. ${ }^{6-9}$ Unfortunately, the utilization of community services is low, and primary care providers (PCPs) have low awareness of existing resources and limited time or interactions with their patients to discuss all available options. ${ }^{10}$ Optimized care would help patients connect with resources that might best meet their needs; however, linking PCPs and community resources for patient guidance in diabetes care remains challenging. ${ }^{11}$

The patient navigator role, which originated from the cancer treatment domain, ${ }^{12}$ has demonstrated effectiveness in improving patient outcomes. ${ }^{13-15}$ In the original model, cancer patient navigators were defined as "trained, culturally sensitive health care workers who provide support and guidance throughout the cancer care continuum helping patients "navigate" through the maze of doctors' offices, clinics, hospitals, outpatient centers, insurance and payment systems, patient-support organizations, and other components of the health care system." 16 Most commonly, the navigators who usually come from health profession occupations navigate eligible patients from the larger community to appropriate and specific health care services and ultimately help with addressing barriers to health service utilization and access.

Distinct from the original definition, we focused on the navigation function in the opposite direction-a function that served to navigate pa-

research support from Sanofi US, Shire, Mallinckrodt, Novartis Pharmaceuticals Corporation, Merck, and Pfizer, Inc.

Corresponding author: Natalia Y. Loskutova, MD, PhD, American Academy of Family Physicians National Research Network, 11400 Tomahawk Creek Pkwy, Leawood, KS 66211 (E-mail: nloskutova@hotmail.com). tients referred from health care systems into the community for appropriate and diverse community services and programs. In addition, we defined the patient navigator model (PNM) based on role or function rather than on professional or occupational fit. Thus the PNM in our study included non-health workers who navigated patients referred from health care clinics for a specified set of navigation services delivered over the telephone.

The objective of this study was to determine the feasibility and acceptability of telephonebased nonprofessional patient navigation for patients with type 2 diabetes, prediabetes, and those at risk for diabetes. The primary mission of the patient navigator in our program was to link patients who have been referred by their family physician to the most appropriate community resources based on their needs and readiness to change. In this feasibility study we explored whether this adapted PNM may be a suitable model to bridge the gap in linking PCP and community resources for diabetes care.

\section{Methods \\ Project Overview}

This was a before/after cohort study, with no control group, conducted as a quality improvement project in 6 primary care practices in Birmingham, Alabama, between November 2012 and August 2013 as a part of the clinical-community partnership "Cities for Life." 17 The Cities for Life program combined a community awareness and engagement campaign with a practice-based pilot; the results of the latter are presented here. The community component consisted of a network of community leaders and organizations that came together to provide support for patients. At the community level, the program sought not only to provide diabetes management resources but also to create a supportive environment for those living with or at risk for diabetes. By using existing community events, Cities for Life representatives set up displays, distributed educational materials, networked with event attendees, and spoke during the events. To complement the event activities, Cities for Life representatives participated in media interviews and disseminated social media posts on $\mathrm{Fa}$ cebook and Twitter to raise awareness about the program. 


\section{Practice Selection and Study Population}

Six local family medicine practices participated in the practice-based pilot component of the program. Participating practices were mostly located in urban areas; practices were owned by hospital/ health systems $(\mathrm{n}=2)$, the federal or state government $(n=2)$, or a large medical group $(n=1)$, whereas 1 was independent. All practices had business/practice managers, administrative staff members, and at least 1 family medicine physician, and all used electronic health record systems. Only 1 practice had a dietician, and none had diabetes care managers.

English-speaking adult patients residing within the Birmingham city limits and receiving services at one of the enrolled practices were invited to participate in the project if they (1) were diagnosed with type 2 diabetes; (2) were at risk for type 2 diabetes (determined by the results of the ADA Risk Test, with a score $\geq 2$ ); or (3) had prediabetes (confirmed by a clinical diagnosis of prediabetes or International Classification of Diseases, 9th Revision, code 790.29 present in the patient health record). Because of limited resources, non-Englishspeaking patients and those residing outside the Birmingham city limits were excluded. The program was introduced to the patients by office staff and clinicians during office visits and through posters and brochures in the waiting rooms. Patients were recruited in primary care clinics by the providers and practice staff during regular visits. The providers used a referral form that was completed by both the patient and the provider. The form served as the initial "screening" for eligibility, included the ADA Risk Test to determine whether the patients were at risk for diabetes, and collected information on basic demographics and clinical measures. ${ }^{18}$ The referral form was developed by the project team and is included in Online Appendix 1. After a patient agreed to participate and completed the form, eligibility for referrals was determined by a treating physician based on the "screening" results and the specifics of an individual patient's diabetes management plan. The patient referral forms for all eligible referred patients were transmitted from the primary care offices to the patient navigators. Informed consents for interviews were obtained from patients and providers, and the project protocol was approved by the American Academy of Family Physicians Institutional Review Board (IRB), the University of Ala-
bama-Birmingham (UAB) IRB, and local health care organization IRBs, as appropriate.

\section{Patient Navigators, Training, and Community Database}

Two patient navigators recruited from 2 of the Cities for Life partner community organizations participated in the project at 0.5 full-time equivalent per navigator. Neither patient navigator had a health care professional license nor provided health care. One worked as the coordinator of the YMCA's Diabetes Prevention Program and held a master's degree in theological science. A second patient navigator worked as a research specialist in the Division of Preventive Medicine at UAB and held a bachelor's degree in sociology. Before the beginning of the program, neither patient navigator had specific patient navigation experience.

The patient navigators lived and worked in the communities they served and were knowledgeable about the community resources utilized in this study. However, a structured audit of community organizations and services was necessary to catalog and assess the existing programs before implementation. The audit was conducted by the project team and Cities for Life partner community organizations. The results informed a database of existing community programs and the selection of community programs that provided services for patients with type 2 diabetes for patient navigation. Before the intervention period, both navigators actively participated in the preintervention planning activities for developing a database and vetting the community resources for the project.

Patient navigators completed training before beginning of the project. The training consisted of two 1.5-hour webinar-based training sessions on patient-centeredness, individualized care plans, motivational interviewing techniques, communication, and tracking. The project team consisting of 2 family physicians and a family medicine department professor trained patient navigators. The project manager participated in training and ongoing review and feedback sessions, and supervised patient navigators' activities. Although there was no formal assessment of patient navigators' skills or competence, the project's qualitative evaluation included measures suggested for use in the assessment of patient navigators, such as satisfaction with navigation, patient self-efficacy, perceived barriers to care, working alliance between primary care 
practices and patient navigators, and cultural competency. ${ }^{19}$ The content of training sessions and additional information can be found in the Cities for Life toolkit on the American Academy of Family Physicians Foundation website (http://toolkit. aafpfoundation.org/).

\section{Intervention Protocol and Patient Navigation}

Participating physicians were asked to refer eligible patients, through patient navigators, to community-based programs over the 9-month intervention period. Each practice was asked to refer at least 30 eligible patients. There was no upper limit on the number of patients referred. To reduce burden on the practices, they were not required to report the total number of eligible patients seen during the referral period nor the number of patients who refused to participate. The referral period started November 1, 2012, and ended July 1, 2013, with patient navigation activities completed by August 1, 2013.

Each patient navigator was assigned 3 practices. Patient navigators provided feedback to providers, patients, and community programs, and maintained patient navigation tracking database using a Web-

Figure 1. Patient navigation workflow.

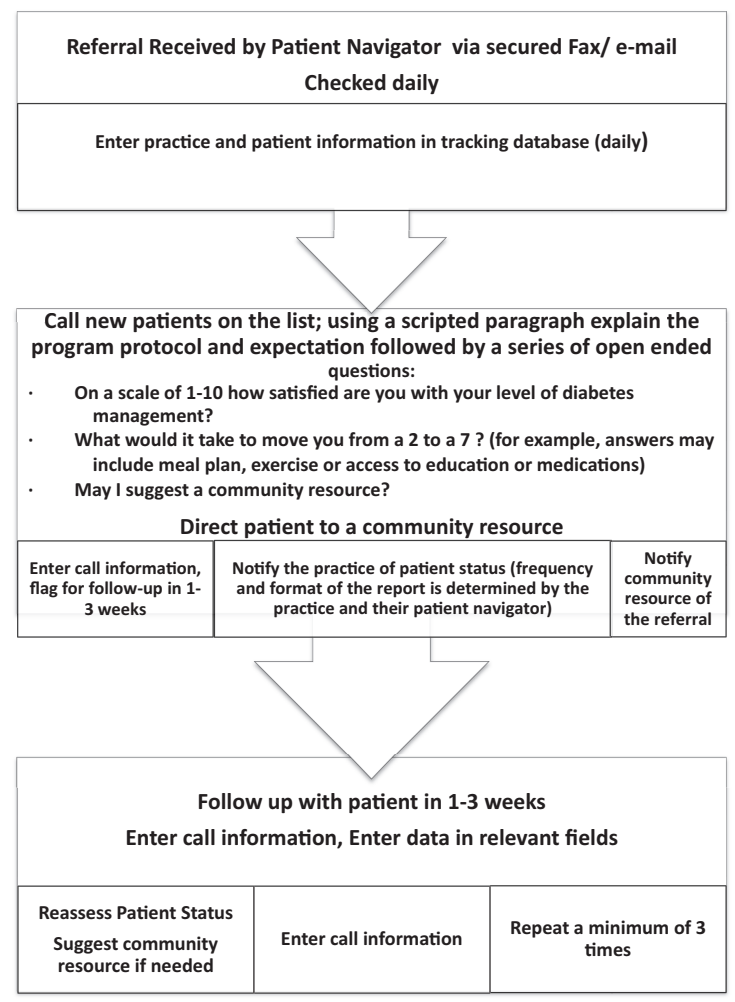

based client relationship management system. An overview of the patient navigation scope and process is presented in Figure 1. Patient navigators were primarily responsible for proactively connecting patients with community-based programs, following patients after referral, and providing information and encouragement. ${ }^{14}$ Patient navigators were not responsible for health education or providing emotional support; rather, they encouraged patients to use appropriate community programs where these services are typically provided. The patient navigators did not meet with the patients in person; the navigation was provided over the telephone. The initial call included introductions and an initial assessment of needs, barriers and limitations, and stages of readiness to change, followed by a suggestion of 2 to 3 community programs and a discussion for next steps. The generic content of the initial call is summarized in Online Appendix 2. Follow-up contacts were conducted by phone. Templates for follow-up letters sent via E-mail and postal mail also were created and available for patient navigators to use for reminders, follow-up, and information sharing. Because of the pilot nature of the program, its focus was primarily on establishing an initial referral/intake system, identifying tailored community resources, and providing information, with limited follow-up contacts. The patient navigators were able to terminate the follow-up contacts as soon as the patient confirmed attendance with a suggested program or after $>5$ consecutive unsuccessful contacts.

Each navigator tried to offer at least 2 community resources that were a good fit for what the patients expressed as their needs, and they let the patients choose which they would like to participate in. The patient navigators provided monthly feedback reports to participating practices and notified community programs when the program was recommended for a patient. The report templates were developed for the patient navigators to use for the practice reports (see the example in Online Appendix 3).

\section{Measures, Data Sources, and Collection Methods}

Data on sociodemographic, insurance, and clinical characteristics were obtained from the clinics' electronic health records and collected as a part of a regular clinical visit. Patient health records were reviewed by practice staff or by approved external individuals. Data extraction was standardized across 
all sites and conducted using the medical record review form developed by the project team members who are experienced in collecting data from primary care practices. The local study coordinator at $\mathrm{UAB}$ trained and supervised practice staff on data collection at all participating practices. Clinical measures, including $\mathrm{HbA}_{1 \mathrm{c}}$, random or fasting glucose concentrations, body mass index (BMI), lipids, and blood pressure, were extracted from visits/measurements dated closest to the referral date but no more than 18 months before ("baseline" measurement). The postintervention clinical data were collected within 1 month after the implementation period (August 2013) and included data from the patient visit closest to the postintervention data collection date.

Patients completed a baseline and end point survey to assess their perception of self-efficacy in diabetes self-management. Self-efficacy was assessed by a hybrid measure developed by the study team based on other diabetes self-efficacy scales, with input from an expert panel and using the principles of "reasonable pragmatism" to make it applicable in the primary care setting. ${ }^{20}$ Various validated and experimental scales were considered for this project; however, all the scales considered had $\geq 20$ items. It is important to note that the patients were recruited during a routine visit to a family physician, and longer assessment tools increase patient and practice burden. Most important, the existing relevant scales partially overlap in content, yet individually they do not include all aspects of self-management relevant to the study, suggesting the need to complete several related questionnaires, which would significantly increase patient burden. ${ }^{21}$ The scale used included 12 questions selected from the Stanford scale, the Diabetes Empowerment Scale, and the Chronic Illness Resources Survey. ${ }^{2-24}$ The final questionnaire is available in Online Appendix 4.

The data on patient barriers, utilization of patient navigation services, and program participation were obtained from the patient navigation tracking database, supplemented by qualitative data from patient, provider, and patient navigator interviews.

Semistructured telephone interviews were conducted with (1) the patient navigators at the end of the intervention (October 2013) and (2) a convenience sample of 10 patients who participated in the project (August-October 2013). In-depth interviews with providers were conducted in each of the
6 practices during site visits at 2 points: baseline (December 2012 through April 2013) and at the end of the implementation phase (June-July 2013). The interviews were conducted by an experienced qualitative researcher and asked questions about experiences with program implementation; challenges, successes, and satisfaction with the program; patient and provider barriers; barriers for participation; and lessons learned.

\section{Statistical Analysis}

Continuous variables were summarized as means \pm standard deviations, and categorical variables were summarized by counts or percentages, as appropriate. The differences in percentages in the before/after measures were assessed using $\chi^{2}$ and $\mathrm{McNemar}$ tests, with $P<.05$ considered statistically significant. Analysis of change in $\mathrm{HbA}_{1 \mathrm{c}}$ was restricted to a subgroup of patients with a diagnosis of diabetes type 2 for whom before/after data were available $(n=42)$. Differences in the mean values of continuous variables, including clinical data and patient selfefficacy level at baseline and after intervention, were tested using multivariate repeated-measures analysis of variance. Age, sex, and all variables that correlated with outcomes of interest at a trend level $(P<.10)$ in the univariate analyses (race, ethnicity, insurance status, weight, and lifestyle) were included in the multivariate analyses as appropriate to assess changes over time. The Little test was conducted to assess data messiness. The test revealed that for all main outcomes of interest the data were missing completely randomly or missing at random, meaning the missing data may be considered "ignorable." Missing data were excluded pairwise on an analysis-by-analysis basis. Statistical analyses were conducted using SAS version 9.4 (SAS Institute Inc., Cary, NC).

Qualitative data were collected, analyzed, and interpreted by an evaluation team consisting of 4 members. One member of the evaluation team joined the project near the end of the study and therefore did not participate in the early data collection activities and was not familiar with the project or the practices. This provided an opportunity to conduct objective telephone interviews with patients and blinded reviews of the de-identified qualitative data. Qualitative and mixed- 
Table 1. Baseline Sample Characteristics of the Patient Sample and Clinical Measures $(\mathbf{n}=179) *$

\begin{tabular}{lc}
\hline Age (years), mean \pm SD & $53.1 \pm 12.2$ \\
Female sex & $131(73.2)$ \\
Race & \\
White & $27(15.1)$ \\
African American & $138(77.1)$ \\
Other & $2(1.1)$ \\
Unknown/missing & $12(6.7)$ \\
Ethnicity & \\
Non-Hispanic & $137(76.5)$ \\
Hispanic & $5(2.8)$ \\
Unknown/missing & $37(20.7)$ \\
Education & \\
Some high school or less & $20(11.2)$ \\
High school graduate & $36(20.1)$ \\
Some college or technical school & $21(11.7)$ \\
College graduate & $26(14.5)$ \\
Postgraduate/professional & $3(1.7)$ \\
Unknown/missing & $73(40.8)$ \\
Insurance & \\
Private & $53(29.6)$ \\
Public (Medicare/Medicaid) & $74(41.3)$ \\
None & $47(26.3)$ \\
Unknown/missing & $5(2.8)$ \\
Diagnosis & $117(65.8)$ \\
Diabetes mellitus type 2 & $15(8.4)$ \\
Prediabetes & $45(25.1)$ \\
At risk & $2(1.1)$ \\
Unknown/missing & \\
Smoking & $26(14.5)$ \\
Current & $33(18.4)$ \\
Former & \\
Never & \\
Unknown/missing & \\
\hline & \\
\hline
\end{tabular}

Data are $\mathrm{n}(\%)$ unless otherwise indicated.

*The sociodemographic, insurance, and smoking data were obtained from the patient electronic health records and were included if collected as part of a regular clinical encounter. $\mathrm{SD}$, standard deviation.

methods data were organized using a templatestyle analysis to identify and categorize the units of interest and themes related to the project objectives. $^{25,26}$ The themes then were broken into subthemes that were supported by quotes from the interviewees. ${ }^{27}$ Thematic analysis was performed through the process of phases to create established, meaningful patterns, and immersion/crystallization analyses were used when appropriate. These dual processes continued until all data relevant to feasibility and acceptability of the PNM were examined and meaningful pat- terns and claims that can be well articulated and substantiated emerged.

\section{Results \\ Baseline Participant Characteristics}

We recruited 179 patients to participate in the program and referred them to the patient navigators. More than half of all participants were women, and the majority were African American (Table 1). The majority had public health insurance and $26.3 \%$ were uninsured. Among all people referred to the patient navigators, 117 (65.4\%) had a diagnosis of diabetes. Of those without a formal diagnosis, 45 were at risk for diabetes according to the ADA Risk Test (score $\geq 2$ ), and 15 had a diagnosis of prediabetes. The prevalence of patient-reported individual risk factors is presented in Table 2.

Overall, the patients reported levels of self-efficacy for diabetes management to be $3.1 \pm 0.8$ (on a scale of 1 to 5 , where $1=$ low/poor and $5=$ high/good) at baseline. About $68.5 \%$ felt overwhelmed by diabetes management demands, and $74.3 \%$ were obese $\left(\mathrm{BMI} \geq 30 \mathrm{~kg} / \mathrm{m}^{2}\right)$.

\section{Clinical Results}

Compared with baseline, there was a clinically meaningful and statistically significant reduction in $\mathrm{HbA}_{1 \mathrm{c}}$ after the intervention $(7.8 \pm 1.9 \%$ vs $7.2 \pm 1.3 \% ; P=.001)$ among a subgroup of patients with an existing diagnosis of type 2 diabetes $(n=42)$. For all patients, compared with baseline there was a reduction in systolic blood pressure $(134.3 \pm 21.3$ vs $130.0 \pm 16.5 \mathrm{mmHg} ; P=.22)$

\section{Table 2. Diabetes Risk Factor Prevalence}

\begin{tabular}{lc}
\hline $\begin{array}{l}\text { ADA Risk Test Risk Factors } \\
\text { (Self-Reported) }\end{array}$ & $\begin{array}{c}\text { Reported as "Yes" } \\
(\mathrm{n}=161)(\%)\end{array}$ \\
\hline I am overweight or obese. & 85.7 \\
I do not exercise regularly. & 67.1 \\
I have a parent, brother, or sister with & 48.4 \\
$\quad$ diabetes. & 77.0 \\
I am age 45 or older. & 75.8 \\
I have high blood pressure. & 76.4 \\
I am of nonwhite race. & 33.5 \\
Cholesterol: I have low HDL (good), high & \\
$\quad$ LDL (bad), or high triglycerides. & 6.2 \\
Women: I had gestational diabetes (while & \\
$\quad$ pregnant) or a baby that weighed $\geq 9$ & \\
pounds at birth. & \\
\hline
\end{tabular}

ADA, American Diabetes Association; HDL, high-density lipoprotein; LDL, low-density lipoprotein. 
Table 3. Clinical Characteristics and Change over Time

\begin{tabular}{|c|c|c|c|}
\hline Clinical Measures & Before & After & $P$ Value \\
\hline $\begin{array}{l}\text { Fasting glucose } \\
\qquad(\mathrm{mg} / \mathrm{dl})\end{array}$ & $129.0 \pm 51.1$ & $124.4 \pm 51.3$ & .85 \\
\hline $\begin{array}{l}\mathrm{HbA}_{1 \mathrm{c}}(\%) \\
\quad \text { (diabetes only) }\end{array}$ & $7.8 \pm 1.9$ & $7.2 \pm 1.3$ & .001 \\
\hline \multicolumn{4}{|l|}{$\begin{array}{l}\text { Blood pressure } \\
\qquad(\mathrm{mmHg})\end{array}$} \\
\hline Systolic & $134.3 \pm 21.3$ & $130.0 \pm 16.5$ & .22 \\
\hline Diastolic & $80.5 \pm 11.0$ & $80.3 \pm 10.3$ & .38 \\
\hline $\begin{array}{l}\text { Body mass index } \\
\qquad\left(\mathrm{kg} / \mathrm{m}^{2}\right)\end{array}$ & $36.1 \pm 8.8$ & $36.2 \pm 8.8$ & .20 \\
\hline $\begin{array}{l}\text { Total cholesterol } \\
\qquad(\mathrm{mg} / \mathrm{dl})\end{array}$ & $180.8 \pm 38.0$ & $178.2 \pm 38.6$ & 1.00 \\
\hline $\begin{array}{l}\text { Low-density } \\
\text { lipoprotein } \\
(\mathrm{mg} / \mathrm{dl})\end{array}$ & $104.5 \pm 34.3$ & $100.4 \pm 30.5$ & .50 \\
\hline $\begin{array}{l}\text { High-density } \\
\text { lipoprotein } \\
\text { (mg/dl) }\end{array}$ & $51.6 \pm 15.9$ & $48.9 \pm 12.9$ & .79 \\
\hline $\begin{array}{l}\text { Triglycerides } \\
\text { (mg/dl) }\end{array}$ & $132.7 \pm 90.3$ & $147.0 \pm 101.1$ & .17 \\
\hline Self-efficacy level* & $3.1 \pm 0.8$ & $3.6 \pm 0.7$ & $<.001$ \\
\hline
\end{tabular}

Data are presented as mean \pm standard deviation. Multivariate analysis of variance tests were used for the before/after analyses. Missing values were excluded on an analysis-by-analysis basis. *Wilcoxon related samples signed rank test; scale, 0 (poor) to 5 (good).

that did not reach statistical significance in the multivariate analyses. Overall, patients reported improvement in their self-efficacy levels $(3.1 \pm 0.8$ vs $3.6 \pm 0.7 ; P<$ .001 ); however, no covariates were significantly associated with the change. There was a trend for sedentary individuals to see a greater increase in their efficacy scores versus those who were not sedentary $(P=.06)$. The proportion of people who felt overwhelmed also decreased from baseline (45.8\% vs $68.5 \% ; P=.001$ ). Similar strong postintervention differences were seen overall in the feeling of being overwhelmed $(P=.0004)$, and the degree of change was dependent on insurance status $(P=.03)$. When the analysis was stratified by insurance, a feeling of being overwhelmed remained unchanged in the privately insured group $(P=.15)$; however, participants without insurance or with public insurance did have significant reductions in the feeling of being overwhelmed $(P=.002$ and $P=.0004$, respectively). No significant changes were observed in body weight, BMI, diastolic blood pressure, or lipids (Table 3).

\section{Program Utilization}

The patient navigators received referral forms for all referred patients and made a total of 1028 calls over 9 months, with an average of 6.1 calls per patient (range, $2-15$ calls). When the patient navigator notes from the tracking system were categorized by whether contact was made with the patient, $69.1 \%$ of all calls included at least some interaction with the patient. A subgroup of 14 patients $(7.8 \%)$ was not reached despite an average of 4.9 attempts (range, $2-8$ attempts) to contact them. The reasons for lack of reach were mostly related to patients not answering the phone or incorrect contact information. On average, the patients spent $120.4 \pm 50.5$ days (range, 1-260 days) in patient navigation.

The patient navigators linked patients to a total of 44 community organizations. A summary of the resources suggested to the patients is provided in Table 4. Patient navigators shared that the most popular resources with the patients were community programs that are free, accessible, and vetted, and the key to addressing patient needs was listening to the patient: "I could usually find a resource that met their [the patient's] need" (patient navigator 2).

\section{Feasibility of Integrating Community Patient Navigators in Primary Care}

Patient navigators each worked with 3 practices and thought working with practices in multiple health systems did not affect program implementation. The patient navigators reported that at times they felt overwhelmed by the number of patients being referred and program tracking demands. The patient navigators highlighted that key facilitators of the process were the resources provided by local community-based resource websites, strong community support, and the existence of good community-based organizations to which patients could be referred.

From a practice perspective, the program was feasible because it did not interrupt the practice's workflow: "I think everything was good. It was not that hard. It was not anything unreasonable" (site coordinator, practice 4).

Overall, practices believed they maintained their workflow processes for monitoring their patients, although some of the practices noticed greater involvement by staff in alerting the physician if patients would be good candidates for the program, more diligence in following up with patients and monitoring their $\mathrm{HbA}_{1 c}$, and, specifically, earlier detection of prediabetes. However, the providers believed that a longer implementation period would be beneficial.

According to the interview data at baseline, the most prevalent barrier for improving quality of care discussed 
Table 4. Community Resources by Category and Activity

\begin{tabular}{|c|c|c|}
\hline Resource & Community Category & Activities \\
\hline 1. Bluff Park United Methodist Church & Church & Zumba \\
\hline 2. Guiding Light Church & & Zumba \\
\hline 3. Macedonia Church & & Zumba \\
\hline 4. St. John AME Church & & Zumba \\
\hline 5. 16th Street Baptist Church & & Exercise classes \\
\hline 6. New Bethlehem Baptist & & Zumba \\
\hline 7. First UMC, Trussville & & Zumba \\
\hline 8. Love Fellowship Christian Center & & Zumba \\
\hline 9. First UMC, Huffman & & Yoga \\
\hline 10. The Summit Church & & Zumba \\
\hline 11. Faith Chapel-Bridge Ministry & & Zumba \\
\hline 12. MTC (More than Conquerors) Church & & Zumba/fitness \\
\hline 13.Gardendale Civic Center & Community center & Exercise classes, spinning \\
\hline 14. Graysville Community Center & & Exercise \\
\hline 15. PEER Community Garden & Community garden & Diet and nutrition \\
\hline 16. Western Community Gardens & & Diet and nutrition \\
\hline 17. St. Vincent's East Support Group & Diabetes support groups & Education/self-management \\
\hline 18. N. Birmingham Library Diabetes Support Group & & Education/self-management \\
\hline 19. Senior Transportation Services & Emergency services & Transportation \\
\hline 20. ADPH Social Worker & & Social services \\
\hline 21. Alabama Farmers Market & Farmer's market & Nutrition and diet \\
\hline 22. East Lake Farmer's Market & & Nutrition and diet \\
\hline 23. Curves & Gym & Exercise and fitness \\
\hline 24. St. Vincent's 119 & & Exercise and fitness \\
\hline 25. Rivera Fitness & & Exercise and fitness \\
\hline 26. Planet Fitness & & Exercise and fitness \\
\hline 27. Next (The Old Sport Plex) & & Exercise and fitness \\
\hline 28. YMCA & Health and wellness & Exercise, wellness, and health education \\
\hline 29. HealthSmart & & $\begin{array}{l}\text { Health screenings, wellness, health education, } \\
\text { and fitness }\end{array}$ \\
\hline 30. Library* & Health education & Health education \\
\hline 31. Cooper Green & Healthcare & Diabetes education \\
\hline 32. Birmingham Health Care & & Primary care physician \\
\hline 33. Diabetes Bridge Clinic & & Education, health care \\
\hline 34. UAB Dental Clinic & & Oral health care \\
\hline 35. Ruffner Mountain & Parks and recreation & Hiking \\
\hline 36. Harriman Park & & Exercise classes \\
\hline 37. Hooper City Parks and Recreation & & Zumba and aerobics classes \\
\hline 38. Ensley Parks and Recreation & & Zumba \\
\hline 39. Alabama Clinical Therapeutic & Research & Diabetes trials \\
\hline 40. UAB Eat Right Weight Management & UAB research project & Nutrition and weight loss \\
\hline 41. ImWeL & & Weight loss management \\
\hline 42. NIDDK & Website & Health education \\
\hline 43. ADA website & & Health education (diabetes) \\
\hline 44. MyDiabetesConnect.com ${ }^{\dagger}$ & & Community resources \\
\hline
\end{tabular}

*Library referrals are not broken down by location.

${ }^{\dagger}$ Resource developed by the community as a part of Cities for Life Program (http://mydiabetesconnect.com/).

ADA, American Diabetes Association; ADPH, Alabama Diabetes Prevention and Control Program; AME, African Methodist Episcopal; MTC, More than Conquerors; NIDDK, National Institutes of Diabetes and Digestive and Kidney Diseases; PEER, Promoting Empowerment and Enrichment Resources; UAB, University of Alabama Birmingham; UMC, United Methodist Church; YMCA, Young Men's Christian Association. 
by the providers and practice staff was the amount of time it takes to educate patients. Because of daily time constraints, providers rely on support staff (nurses, physician assistants, residents, and specialists) to provide the education and counseling they do not have time to engage in themselves. Other limitations included practice staff being underutilized, time constraints, and failure to follow diabetes checkup protocol. Providers considered the main patient challenges in effectively managing their disease to include a lack of readiness to change, a lack of general compliance, limited resources, transportation, low socioeconomic status, a lack of proper nutrition, limited/difficult access to care and programs, medication cost, health literacy issues, and fear and denial among patients.

Patients reported some internal barriers, such as lack of self-motivation, and external barriers such as caregiver responsibilities, lack of transportation, and prohibitive community program costs. From information about 179 participants reported by patient navigators in the patient navigation tracking database, upon initial assessment, $16.8 \%$ of patients shared that they had low self-management skills, $2.8 \%$ could not afford medications, and $13.9 \%$ had other various barriers.

Although some project-related challenges were present, including programmatic demands for collecting data, a relatively short project duration, and competing or inaccessible community programs, the ability to engage providers and practice staff, involve a variety of community organizations, recruit the target number of patients, recruit and train the patient navigators from the community, and implement the program and data collection according to the initial protocol, all suggest that integrating community patient navigators in primary care is feasible.

\section{Acceptability of the PNM and Services}

Overall, interview data indicated that patients were satisfied with the program and the majority would recommend the program to family and friends. When asked whether they would use the program in the future for their health care needs, $90 \%$ of patients interviewed strongly agreed/agreed. The patient navigators provided an opportunity for patients to receive additional specialized education that served to reinforce what they already knew or to address gaps in their knowledge. Information patients received from the patient navigators not only helped fill knowledge gaps but also empow- ered them to put into action the information they received and gave them the opportunity to ask specific questions. All interviewed patients reported experiencing some improvements in health, emotional status, or self-confidence as a result of participating in the program. Four patients reported losing a significant amount of weight. Patient navigators, whom patients found to be helpful, courteous, and caring, played an important role in patient satisfaction. Most of all, patients appreciated the check-in calls and information provided by the patient navigators.

Providers' acceptance of the PNM was high. Providers believed that the project offered an opportunity to help patients address their barriers by giving the patients more opportunities to selfmanage their diabetes. According to providers, patient navigation had a tangible impact on patients, including an apparent increase in overall happiness and satisfaction. One provider from practice 1 noted, "I have a positive attitude about the project ... [and] would do it again."

The providers perceived the patient navigators as personable, approachable, able to establish good rapport with the patients, and, overall, potentially effective for increasing patient compliance. The providers uniformly were very supportive of the PNM: "Overall loved the concept" (provider, practice 2). The patient navigators also shared their overall acceptance for the project: "Loved the project and [was] never so sad for a project to end" (patient navigator 2).

\section{Discussion}

We sought to determine the feasibility and acceptability of community organization-provided, telephone-based patient navigation for patients with type 2 diabetes, with prediabetes, and at risk for diabetes. A novel aspect of the project was using the PNM through community organizations to establish a referral/intake system, identify patient-tailored community resources, and provide information. The PNM used for this project was designed to promote comprehensive care by linking patients referred by primary care offices to community programs to assist them in self-managing their disease.

Several studies have evaluated the PNM, demonstrating that it can improve health. ${ }^{14,15,28} \mathrm{tk}$; 3 The results of our study corroborate previous 
findings and demonstrate that glycemic control and patient self-efficacy levels improved among patients after participating in telephone-based patient navigation. The observed effects of a $0.6 \%$ change in $\mathrm{HbA}_{1 \mathrm{c}}$ were comparable with those reported in meta-analyses and systematic reviews of pharmaceutical agents for treating diabetes and is considered to be clinically significant. $^{29,30}$ Self-efficacy has been strongly associated with better adherence to diabetes treatment recommendations and improved patient outcomes. ${ }^{31}$ Current evidence suggests that incorporating self-efficacy in health assessment and interventions to increase a person's perceived ability to self-manage is beneficial for improved diabetes care. ${ }^{32,33}$ The results of this study should be interpreted with caution, however, since it did not have a control group because of its feasibility nature. Future studies with the use of a comparator group should be conducted to establish the effectiveness of the intervention.

The results of our study indicate that patient navigators need to be knowledgeable about community resources, culturally sensitive, and possess appropriate skills, such as motivational interviewing techniques and listening skills, which proved to be important for successful implementation. Understanding the context in which the practices work provided a view of the practices, the patients, and the environment in which the project operated. Knowing and anticipating patient barriers could prompt future program teams to explore solutions before implementation and help patient navigators prepare for their patient encounters, including strategies to manage patient apathy and the patient navigators' own frustration and burnout.

Behavior modification counseling is time consuming, and time constraints are one of the key challenges shared by providers. The patient navigators performed an intermediate role between several different types of patient support staff in this project. They did not physically meet with patients as cancer and HIV navigators often do. Patient navigators who physically meet with patients can also take on a peer mentoring role that was not the intent of the patient navigators in this project. The navigator role in this project was very similar to that of the community health education and resource liaisons as described by Holtrop et al. ${ }^{34}$ In their model, the navigators were limited to
3 calls per patient, whereas in this project the navigators averaged over 6 calls per patient. In this regard, the present patient navigation activities were somewhere between a peer mentor, a case manager, and a community health education and resource liaison, with a limited focus on linking patients who have been referred by their family physician to the most appropriate community resources based on their needs and readiness to change. One full-time equivalent patient navigator handled $>160$ referrals from 6 primary care practices in less than 12 months, indicating that despite the high number of contacts the process was fairly efficient and practical for the defined scope of work. Given the variability in patient navigator definitions and scope of work across studies, we believe that if the patient navigator's scope is expanded beyond that tested in this study, additional studies should examine the feasibility, workload, and optimal patient-to-navigator ratios. Primary care providers successfully recruited a targeted number of patients for participation in the project and referred them to community programs through patient navigation, with improved patient status and no changes in practice workflow, demonstrating the feasibility of this approach.

\section{Acceptability}

The process was well received, with high levels of satisfaction with the patient navigation process reported by the providers, patients, and patient navigators. The services most appreciated by the patients were information provided by patient navigators and check-in calls. Patients' appreciation of the calls and assistance they received from the patient navigators significantly contributed to satisfaction with the program. To increase patient participation and promote behavioral changes, it helps if community resources are free or very low cost, vetted, and accessible. One of the patient navigators stated, "I thought I would be using hundreds of resources but the needs with most of my patients had to fall into free and accessible programs." The observation of our study related to greater improvements in the feeling of being overwhelmed among uninsured patients suggests the potentially greater applicability of this model for uninsured and disadvantaged patients. 


\section{Considerations and Future Directions}

The results of our study should be interpreted with caution because of the study design; however, the observed changes in patient clinical and self-efficacy variables and confirmed feasibility suggest that the model could be tested in the future randomized controlled trial. It is important to note that patients were contacted for the interviews several months after the completion of the project; thus the interviews were based on recall. In addition, the relatively short duration of the study led to some missing posttest data: about a quarter of the patients $(23.5 \%)$ did not have a follow-up appointment with their provider by the time the study concluded. A longer study duration could resolve that issue. It was also not feasible to collect data on the number of all eligible patients seen during the study period because this would introduce additional burden on the practice staff and would affect the feasibility of the model implementation. Given the overall promising results of this pilot, we plan to explore these elements of the program, in addition to the potential programrelated and external factors driving the observed changes in clinical and other relevant measures, in future studies. Future controlled, pragmatic clinical trials over a longer period of time should include measures of the actual uptake of community-based programs and explore whether the results could be attributed to patient navigation itself or to community-based program participation. Further studies also need to investigate the most effective components of patient navigation. Studies of the cost-effectiveness of patient navigation, optimal workload, and optimal interaction frequency with patients and providers, as well as the specific needs of patients with diabetes with the highest potential to be addressed by the patient navigators, will provide the necessary basis for health care delivery implementation and reimbursement decisions. In addition, because of the limited availability of assessment measures outside of cancer care, relevant future work should focus on developing measures and tools for standardized patient navigation programmatic evaluation in diabetes care and other chronic conditions. ${ }^{19}$ Overall, the results of our study contribute to the exploration of muchneeded primary care models of care that help to connect patients with community programs for resources, patient guidance, and support in diabetes care.

\section{Conclusion}

These results suggest that the PNM shows promise in linking primary care physicians and community resources for promoting lifestyle modification among people living with or at risk for type 2 diabetes. Moreover, this model showed significant improvement in patients' glycemic control and level of self-efficacy for diabetes care, as well as acceptability to patients and providers. The results of this work demonstrate the feasibility of adopting a PNM for diabetes care in primary care. The patient navigation approach shows promise in addressing the need for lengthy discussions of patient lifestyle and self-management strategies by providers when the navigator is endorsed by the provider.

The authors thank all participants of this project and the City of Birmingham and its citizens. The authors acknowledge the UAB Department of Family \& Community Medicine, UAB HealthSmart, and the YMCA of Greater Birmingham for providing essential expertise, staff, and support.

\section{References}

1. National Diabetes Statistics Report: estimates of diabetes and its burden in the United States. Atlanta: US Department of Health and Human Services; 2014.

2. American Diabetes Association. Standards of medical care in diabetes-2014. Diabetes Care 2014; 37(Suppl 1):S14-80.

3. Starfield B, Shi L, Macinko J. Contribution of primary care to health systems and health. Milbank Q 2005;83:457-502.

4. Marrero DG, Ard J, Delamater AM, et al. Twentyfirst century behavioral medicine: a context for empowering clinicians and patients with diabetes: a consensus report. Diabetes Care 2013;36:46370 .

5. Brownson RC, Housemann RA, Brown DR, et al. Promoting physical activity in rural communities: walking trail access, use, and effects. Am J Prev Med 2000;18:235-41.

6. Auslander WF, Haire-Joshu D, Houston C, Dreitzer D, Williams JH. The eat well, live well nutrition program - dietary changes in African American women by activation. Presented at: the National Institutes of Health Conference on Psychosocial Treatments, Bethesda, MD (1996).

7. Haire-Joshu D, Brownson R, Schechtman K, Nanney S, Houston C, Auslander W. A community research partnership to improve the diet of African Americans. Am J Health Behav 2001;25:140-6. 
8. Haire-Joshu D, Nanney MS. Prevention of overweight and obesity in children: influences on the food environment. Diabetes Educ 2002;28:415-23.

9. Perry CL, Lytle LA, Feldman H, et al. Effects of the Child and Adolescent Trial for Cardiovascular Health (CATCH) on fruit and vegetable intake. J Nutr Educ 1998;30:354-60.

10. Etz RS, Cohen DJ, Woolf SH, et al. Bridging primary care practices and communities to promote healthy behaviors. Am J Prev Med 2008;35(5 Suppl):S390-7.

11. Porterfield DS, Hinnant LW, Kane H, Horne J, McAleer K, Roussel A. Linkages between clinical practices and community organizations for prevention: a literature review and environmental scan. Am J Prev Med 2012;42(6 Suppl 2):S163-71

12. Freeman HP, Rodriguez RL. History and principles of patient navigation. Cancer 2011;117(15 Suppl): $3539-42$.

13. Battaglia TA, Bak SM, Heeren T, et al. Boston Patient Navigation Research Program: the impact of navigation on time to diagnostic resolution after abnormal cancer screening. Cancer Epidemiol Biomarkers Prev 2012;21:1645-54.

14. Dohan D, Schrag D. Using navigators to improve care of underserved patients: current practices and approaches. Cancer 2005;104:848-55.

15. Raj A, Ko N, Battaglia TA, Chabner BA, Moy B. Patient navigation for underserved patients diagnosed with breast cancer. Oncologist 2012;17:1027-31.

16. National Cancer Institute. NCI Center to Reduce Cancer Health Disparities. Available from: http:// crchd.cancer.gov/pnp/what-are.html/. Accessed November 23, 2015.

17. American Academy of Family Physicians. Cities for Life: community health promotion for the management of diabetes in the patient-centered medical home. Available from: http://www.aafp.org/patientcare/nrn/studies/all/cities-for-life.html. Accessed December 16, 2015.

18. American Diabetes Association. Are you at risk for type 2 diabetes? Available from: http://www.diabetes.org/ assets/pdfs/at-risk/risk-test-paper-version.pdf. Accessed November 23, 2015.

19. Fiscella K, Ransom S, Jean-Pierre P, et al. Patientreported outcome measures suitable to assessment of patient navigation. Cancer 2011;117(15 Suppl): 3603-17.

20. Snyder CF, Watson ME, Jackson JD, Cella D, Halyard MY; Mayo/FDA Patient-Reported Outcomes Consensus Meeting Group. Patient-reported outcome instrument selection: designing a measurement strategy. Value Health 2007; 10(Suppl 2):S76-85.

21. Rolstad S, Adler J, Ryden A. Response burden and questionnaire length: is shorter better? A review and meta-analysis. Value Health 2011;14:1101-8.
22. Glasgow RE, Toobert DJ, Barrera M Jr, Strycker LA. The Chronic Illness Resources Survey: crossvalidation and sensitivity to intervention. Health Educ Res 2005;20:402-9.

23. Anderson RM, Fitzgerald JT, Gruppen LD, Funnell MM, Oh MS. The Diabetes Empowerment Scale-Short Form (DES-SF). Diabetes Care 2003; 26:1641-2.

24. Stanford Patient Education Research Center. Diabetes self-efficacy scale. Available from: http:// patienteducation.stanford.edu/research/sediabetes. html. Accessed December 16, 2015.

25. Cohen DJ, Crabtree BF. Evaluative criteria for qualitative research in health care: controversies and recommendations. Ann Fam Med 2008;6: 331-9.

26. Crabtree BF, Miller WL. A template approach to text analysis: developing and using codebooks. In: Doing qualitative research. Research methods for primary care, vol. 3. Newbury Park, CA: Sage Publications;1999: 93-109.

27. Crabtree BF, Miller WL. A qualitative approach to primary care research: the long interview. Fam Med 1991;23:145-51.

28. Battaglia TA, McCloskey L, Caron SE, et al. Feasibility of chronic disease patient navigation in an urban primary care practice. J Ambul Care Manage 2012;35:38-49.

29. Sun YN, Zhou Y, Chen X, Che WS, Leung SW. The efficacy of dapagliflozin combined with hypoglycaemic drugs in treating type 2 diabetes mellitus: meta-analysis of randomised controlled trials. BMJ Open 2014;4:e004619.

30. Waugh N, Cummins E, Royle P, et al. Newer agents for blood glucose control in type 2 diabetes: systematic review and economic evaluation. Health Technol Assess 2010;14:1-248.

31. Mishali M, Omer H, Heymann AD. The importance of measuring self-efficacy in patients with diabetes. Fam Pract 2011;28:82-7.

32. Gherman A, Schnur J, Montgomery G, Sassu R, Veresiu I, David D. How are adherent people more likely to think? A meta-analysis of health beliefs and diabetes self-care. Diabetes Educ 2011; 37:392-408.

33. Harvey JN, Lawson VL. The importance of health belief models in determining self-care behaviour in diabetes. Diabet Med 2009;26:5-13.

34. Holtrop JS, Dosh SA, Torres T, Thum YM. The community health educator referral liaison (CHERL): a primary care practice role for promoting healthy behaviors. Am J Prev Med 2008; 35(5 Suppl):S365-72. 


\section{Appendix 1}

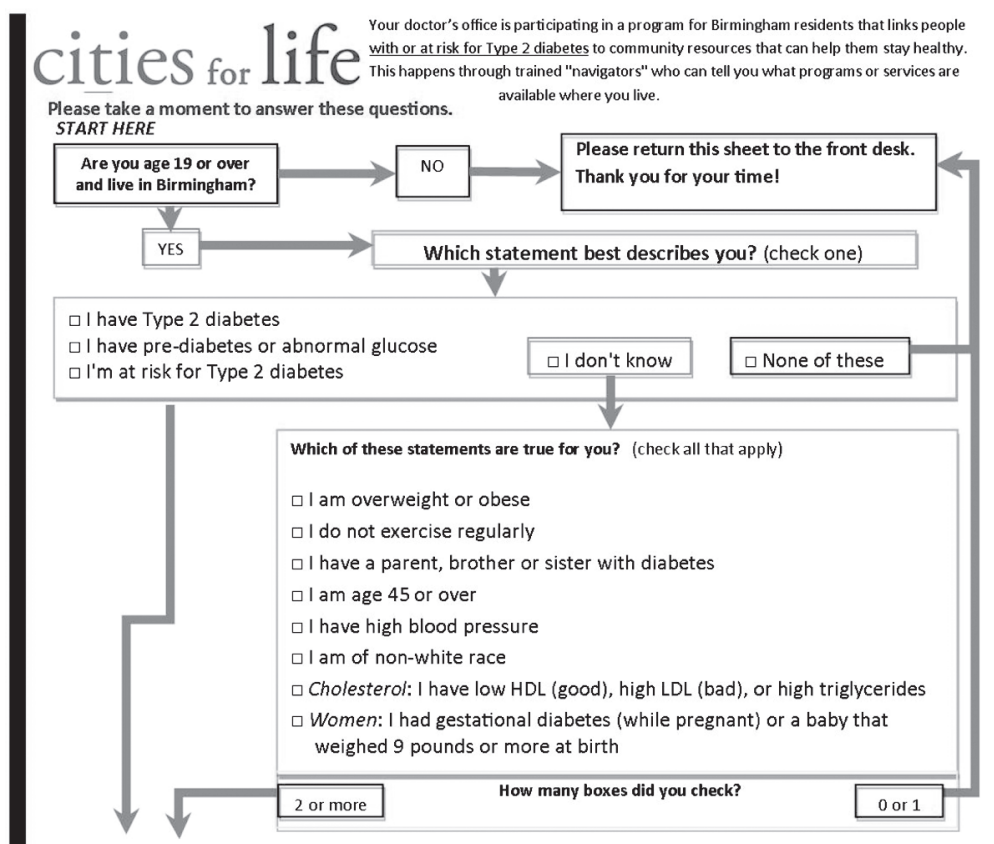

Provide your name and contact information (please print) in the box below.

Hold on to this sheet and talk to your doctor about it during your visit today.

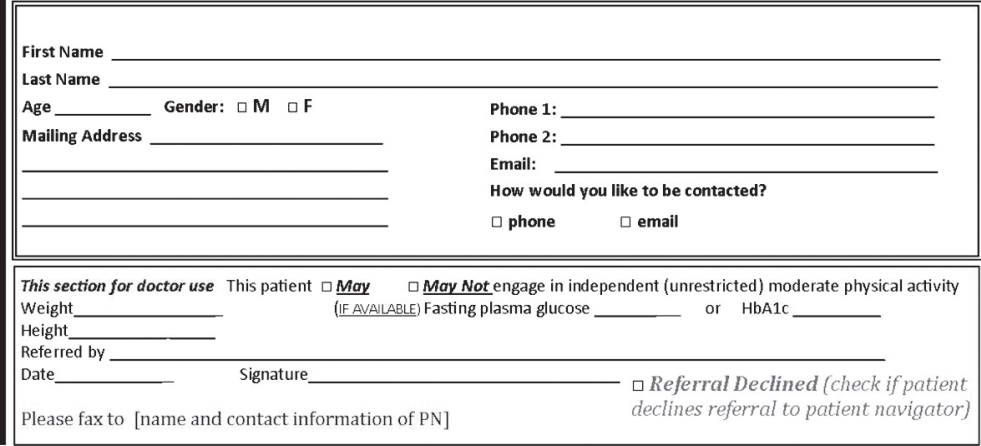

\section{Appendix 2}

Referral Form for Patient Navigation

Cities for Life Interview Questions Script for Intake Patient Navigation Call

1. Build the Relationship

A. Introduce self and program: Cities for Life is a diabetes management pilot program led by the American Academy of Family Physicians Foundation with support from Sanofi US to connect people living with diabetes in Birmingham, Alabama, to community-based programs and services that can help them manage their condition.

B. Confirm participant's name, practice, neighborhood, diagnosis, and any other pertinent information.
C. Go over consent and final interview expectations.

- Ask them if they'd like to do a phone interview (in a couple of months?) with us.

- Explain that you will mail them the consent form with the return envelope to National Research Network address.

- explain that you will call them back in 1 week to go over the consent and ask them to mail it back in the prepaid envelope.

- Explain who will do the final interview.

2. Listen and Learn

A. How/when did you find out you had diabetes? Have you tried controlling diabetes 
before? What have you tried? What was the outcome?

B. Note any lifestyle barriers (time, finances, transportation, language, family).

C. Note interests and any previous successes.

D. On a scale of 1 to 10 , how ready are you to try something new to address your health? (If answer is 10, move forward. If less than 10 (eg, 8), ask "Why not a 10 ?" and note barriers.
3. Prepare to Refer

A. What are you most interested in trying (fitness, nutrition, support group)?

B. What Community Based Organization have you heard of? (Navigate to this if they mention one of ours. If not, take notes.)

C. Would you mind if I made a suggestion or two?

4. Navigate

A. Offer the program that best fits the participant's desires, interests, and accessibility.

\section{Appendix 3}

\section{Feedback Report}

cities for life

Date:

Practice: [PRACTICE NAME]

Dear Dr.[Name]:

Thank you for the opportunity to provide navigation services to your patients with or at risk for Type 2 diabetes through the AAFP Cities for Life program. Below is an individualized feedback report showing the number of times we contacted your patient and the results. To protect confidentiality, patients are only identified by their

Cities for Life ID and your Internal ID. You can match this report to the individual to which it pertains using the Referral Tracking Form you maintained at your practice. The letters are your practice code; the number is the order in which patients were referred. If you have any questions about this report or the services your patient received, please don't hesitate to contact me.

Sincerely,

[NAME]

Cities for Life Patient Navigator Phone: Email:

CfL ID: HFM01 Internal ID: $3491 \quad$ Referral Date: $\quad$ Total Contacts: 5

Action / Result

Recommended < NAME OF THE PROGRAM > Diabetes Support Group. Sent info in the mail and followed up. Had not attended. 


\section{Patient Survey}

Please check the condition that best applies to you:

$\square$ I am at risk for diabetes $\quad \square$ I have diabetes $\square$ Don't know

Please rate on a scale from 1 to 5 the statements below regarding how you manage your risk for diabetes [or] your diabetes. One (1) means not at all OR you never do this and five (5) means very much OR you do this often.

\begin{tabular}{|c|c|c|c|c|c|}
\hline I am confident I can... & $\begin{array}{l}\text { Not } \\
\text { at all }\end{array}$ & & & $\rightarrow$ & $\begin{array}{l}\text { Very } \\
\text { much }\end{array}$ \\
\hline Control my risk for diabetes [or] my diabetes. & 1 & 2 & 3 & 4 & 5 \\
\hline $\begin{array}{l}\text { Prevent my risk for diabetes [or] my diabetes from interfering } \\
\text { in my daily activities (such as work, family obligations, and } \\
\text { recreation). }\end{array}$ & 1 & 2 & 3 & 4 & 5 \\
\hline Follow my diet. & 1 & 2 & 3 & 4 & 5 \\
\hline $\begin{array}{l}\text { Plan for } 30 \text { minutes of exercise per day on most days each } \\
\text { week. }\end{array}$ & 1 & 2 & 3 & 4 & 5 \\
\hline \multicolumn{6}{|l|}{ I frequently ... } \\
\hline $\begin{array}{l}\text { Attend organized programs (such as group meetings, } \\
\text { individual counseling, wellness programs, exercise programs) } \\
\text { to help me manage my risk for diabetes [or] my diabetes. }\end{array}$ & 1 & 2 & 3 & 4 & 5 \\
\hline $\begin{array}{l}\text { Think about or review my progress in managing my risk for } \\
\text { diabetes [or] my diabetes. }\end{array}$ & 1 & 2 & 3 & 4 & 5 \\
\hline $\begin{array}{l}\text { Re-arrange my schedule so I can better manage my risk for } \\
\text { diabetes [or] my diabetes. }\end{array}$ & 1 & 2 & 3 & 4 & 5 \\
\hline $\begin{array}{l}\text { Focus on things I did well to manage my risk for diabetes [or] } \\
\text { my diabetes instead of those things I did not do well. }\end{array}$ & 1 & 2 & 3 & 4 & 5 \\
\hline $\begin{array}{l}\text { Eat healthy, low-calorie foods to manage my risk for diabetes } \\
\text { [or] my diabetes. }\end{array}$ & 1 & 2 & 3 & 4 & 5 \\
\hline Exercise to manage my risk for diabetes [or] my diabetes. & 1 & 2 & 3 & 4 & 5 \\
\hline \multicolumn{6}{|l|}{ I feel... } \\
\hline $\begin{array}{l}\text { Overwhelmed by the demands of managing my risk for } \\
\text { diabetes [or] my diabetes. }\end{array}$ & 1 & 2 & 3 & 4 & 5 \\
\hline I am failing to manage my risk for diabetes [or] my diabetes. & 1 & 2 & 3 & 4 & 5 \\
\hline
\end{tabular}

Thank you for completing this survey. 